\title{
Transient temperature performance of an integrated micro-thermal system
}

\author{
Linan Jiang $\dagger$, Man Wong $\ddagger$ and Yitshak Zohar $† \S$ \\ $\dagger$ Department of Mechanical Engineering, The Hong Kong University of Science and \\ Technology, Clear Water Bay, Kowloon, Hong Kong \\ $\ddagger$ Department of Electrical and Electronic Engineering, The Hong Kong University of \\ Science and Technology, Clear Water Bay, Kowloon, Hong Kong \\ E-mail: mezohar@ust.hk
}

Received 21 January 2000, in final form 10 May 2000

\begin{abstract}
A novel integrated thermal microsystem was designed and fabricated with a heater, microchannels and distributed temperature sensors. This device allows, for the first time, an experimental study of the transient behavior of a thermal microsystem. The transient temperature behavior of the device was studied for a variety of heater power levels and forced convection flow rates, where DI water was used as the working fluid. Both heating-up rise time and cooling-down fall time due to a step current input were determined for natural and forced convection heat transfer. The transient temperature response to a sinusoidal power input was also investigated. The resulting temperature distribution was measured as a function of the input signal and the flow rate. The step response under natural convection is exponential for both heating and cooling processes. However, under forced convection, the heating-up time response exhibits a clear overshoot. The response time for both heating and cooling process is about four times faster than that for the natural convection case.

Furthermore, under certain conditions, the periodic temperature response can exhibit a large peak-peak temperature without the occurrence of dry-out phenomenon.
\end{abstract}

(Some figures in this article are in colour only in the electronic version; see www.iop.org)

\section{Introduction}

The introduction of microelectronics especially in the form of ULSI (ultra large scale integration) technologies offers an increasing number of gates per chip, to which the present computer technology owes much. The net result of the demand for faster circuits with increased interaction is a higher power density, since a higher switching speed requires more electrical power. The increased power density leads to a higher operational temperature, which limits the device performance. Therefore cooling problems are becoming acute for high-speed logic chips, and an efficient cooling system is required to maintain an isothermal environment in the presence of highly transient thermal loads. Direct liquid cooling has emerged as one of the most promising thermal management techniques for microsystems, where the control of both the operating temperature and the temperature cycling is still a challenging task.

A true revolution in chemical and biochemical analysis has been brought about by micromachining technology, with the introduction of new micromachined biomedical systems, such as the micro total analysis system, microflow cytometry and microcapillary electrophoresis. The microfabricated polymerase chain reaction chamber (PCR) is becoming an important tool in biomedical research such as DNA analysis

$\S$ Author to whom correspondence should be addressed. because of its advantages of uniform temperature, short cycle times and small volume [1-4]. The unsteady temperature field of a microsystem presents new potential applications for MEMS devices where controlled temperature cycling is required. A basic understanding of the unsteady heat transfer processes within thermal microsystems is, therefore, vital for the proper design of such systems $[5,6]$.

Steady-state heat transfer in microchannel devices and its several possible applications has been addressed. However, little attention has been given to the transient heat transfer in microchannels. Zumbrunnen [7] developed a theoretical model and presented numerical simulations for transient convective heat transfer in planar stagnation flows with timevarying surface heat flux and temperature. The results indicate that the time response is chiefly governed by the velocity gradient in the free stream. For a sinusoidal fluctuation with a specific amplitude, departures from steadystate heat-transfer coefficients approach limiting values as the fluctuation frequency increases. Rujano and Rahman [8] presented numerical simulations of the transient response of microchannel heat sinks in a silicon wafer, analyzing step and pulsed variations of the input heat load. They investigated the dependence of the device transient thermal performance on a variety of parameters such as channel depth, width, length, spacing between channels, Reynolds number and the solid to fluid thermal conductivity ratio. However, 


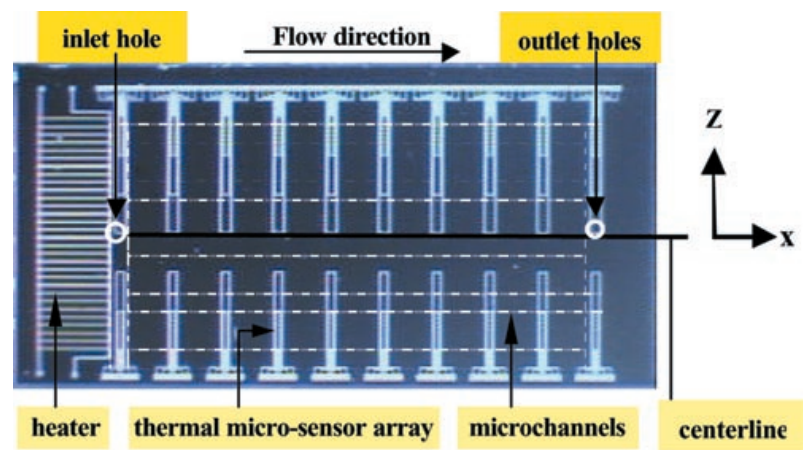

Figure 1. A photograph of a microsystem with a localized heater, buried microchannels and temperature microsensors.

the research on unsteady micro heat transfer is largely limited to theoretical analysis or numerical simulations. No consistent experimental data is available on the transient response of thermal microsystems to facilitate validation of the computational results.

In this work, the transient performance of a microchannel heat sink is experimentally investigated using water as the forced-convection fluid. The time-varying temperature field resulting from step and sinusoidal changes of the input power is studied.

\section{Device design and fabrication}

The thermal microsystem was designed to include a localized heater, distributed temperature micro-sensors and a microchannel array $[9,10]$. The heater and sensors were fabricated by surface micromachining using doped polysilicon. A unique approach of a maskless, self-aligned and self-stopped silicon etch between two bonded wafers was utilized to construct the microchannels. The detail fabrication process has been described elsewhere [11]. A photograph of a fabricated device is shown in figure 1. The heater and the distributed temperature sensors are visible, while the broken lines indicate the location of the buried channels. Thirty-four microchannels with diamond-shaped cross sections, shown in figure 2, were formed with hydraulic diameters of about $80 \mu \mathrm{m}$ and lengths of $18.6 \mathrm{~mm}$ in a single die. The channels were collected by two common passages connected to the inlet and outlet bores. The die size was $12 \mathrm{~mm} \times 25 \mathrm{~mm}$, the size of the temperature sensing elements was $4 \mu \mathrm{m} \times 4 \mu \mathrm{m} \times 0.4 \mu \mathrm{m}$, and the localized heater occupied an area of about $2.8 \mathrm{~mm} \times 8.5 \mathrm{~mm}$.

\section{Experimental set-up}

The experimental apparatus shown in figure 3 consisted of two parts [12]: (i) an external fluid-handling system and (ii) a thermal microsystem test chip. The external system included a high-pressure gas source, a water tank, pressure gages, valves, a $1 \mu \mathrm{m}$ filter, inlet/outlet adapters, a cold-water container, a graduated container for volumetric measurement, a power source, a function generator, a multimeter, an oscilloscope and a data acquisition system. The test chip was packaged on a PCB with designed metal pattern for I/O connections, to which the leads of the heater and sensors were

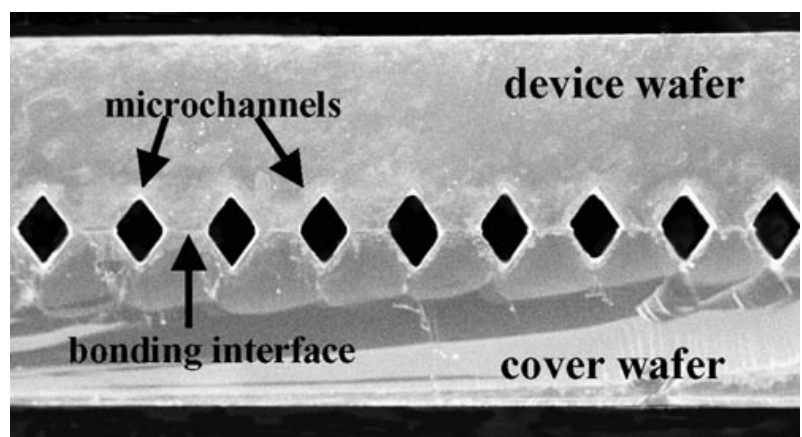

Figure 2. A cross sectional SEM micrograph of the microchannel heat sink.

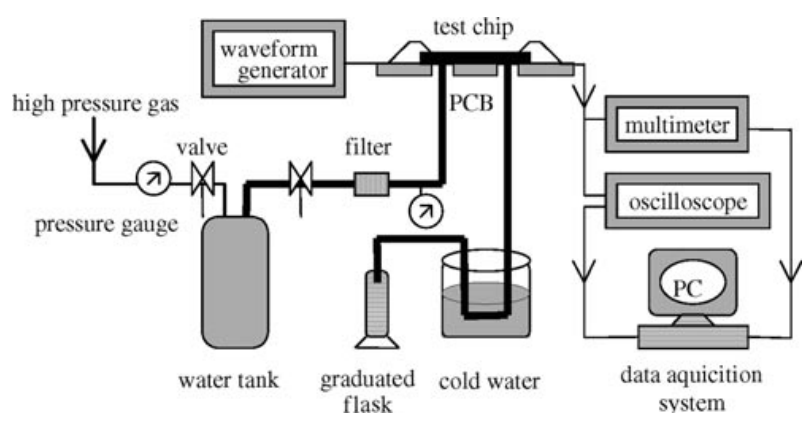

Figure 3. Schematic diagram of the experimental set-up.

connected by wire bonds. DI water was used as the working fluid, and the water was supplied from the pressurized tank at room temperature. The driving pressure could be adjusted by a pressure regulator and a control valve. The water was passed, before entering the micro-channels, through a $1 \mu \mathrm{m}$ filter in order to prevent channel plugging. The adapters, connecting the external fluid-handling system to the microdevice inlet/outlet, enabled the flow of water to pass through the entire system without leakage. The exit fluid from the device outlet was condensed in cold water, enabling the measurement of the volume flow rate with the graduated container. The unsteady power input to the heater was controlled by a HP 33120 function waveform generator. The sensor-array output was simultaneously recorded for selected test conditions by the data acquisition system, which included a Tektronix TDS 460A digitizing oscilloscope, a multimeter and a computer.

The heater, the temperature sensors and the microchannels were calibrated prior to the measurements. The calibration results indicated that the integrated thermal system could be used for the experimental study of the transient temperature field. Moreover, the spanwise temperature distribution was found to be fairly uniform. Therefore, only the output of the sensors along the device centerline was recorded in the present study, in order to analyze the device transient behavior [12].

\section{Device time response to a step-current input}

The transient temperature field, due to a step-current input, was measured and analyzed for two test conditions: (i) no flow within the microchannels (natural convection), 


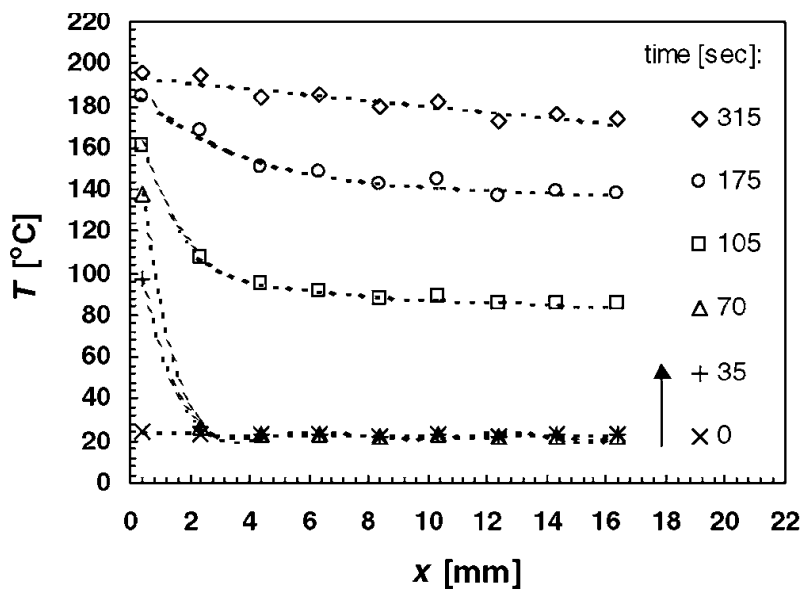

(a)

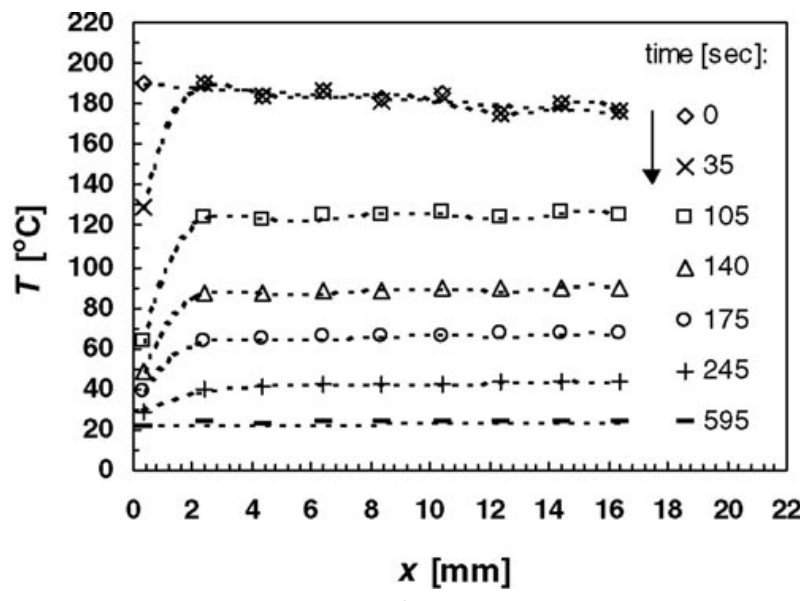

(b)

Figure 4. Transient temperature distribution along the device to a step-current input under natural convection for: $(a)$ the heating-up process and $(b)$ the cooling-down process. $(q=3.2 \mathrm{~W}$.)

and (ii) water flow through the microchannels (forced convection).

\subsection{Transient temperature under natural convection}

4.1.1. Measured time-dependent temperature field. The time response of the device under natural convection from the chip to the air was investigated first. The heater was powered by a step-current signal such that the resulting power input, $q$, ranged from 0.2 to $3.2 \mathrm{~W}$. After the device had reached a steady state, the power was suddenly turned off. The resulting transient temperature distributions along the device centerline, indicated in figure 1 , for both heating and cooling process are shown in figure 4. In the heating-up process, figure 4(a), the temperature at the localized heater increases sharply within the initial $70 \mathrm{~s}$, while there is no temperature change further away from the heater. The temperature on the device surface then increases, having a nonlinear spatial distribution. The temperature field reaches a steady state after about $315 \mathrm{~s}$, and the spatial distribution is almost linear. In the cooling-down process, figure $4(b)$, the temperature at the heater drops quickly within the initial $35 \mathrm{~s}$ while the temperature elsewhere barely changes. The possible reason may be that the heater itself locally provides a larger surface

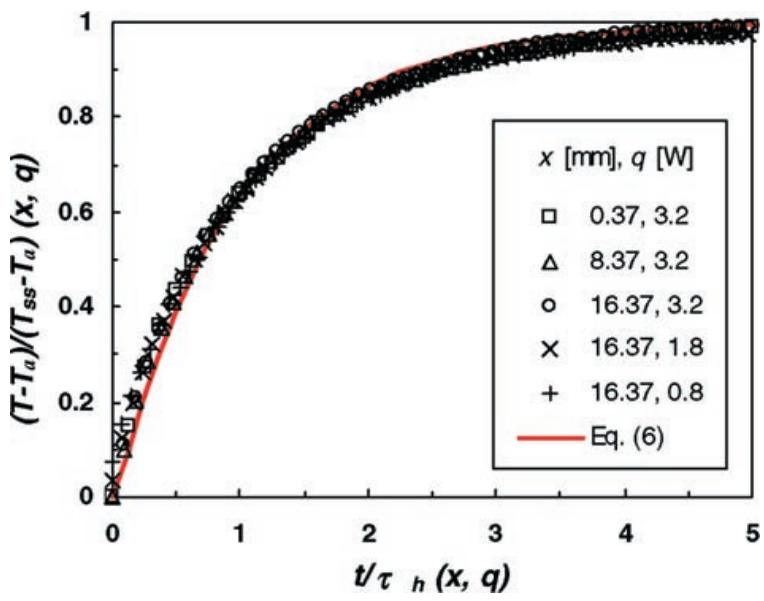

(a)

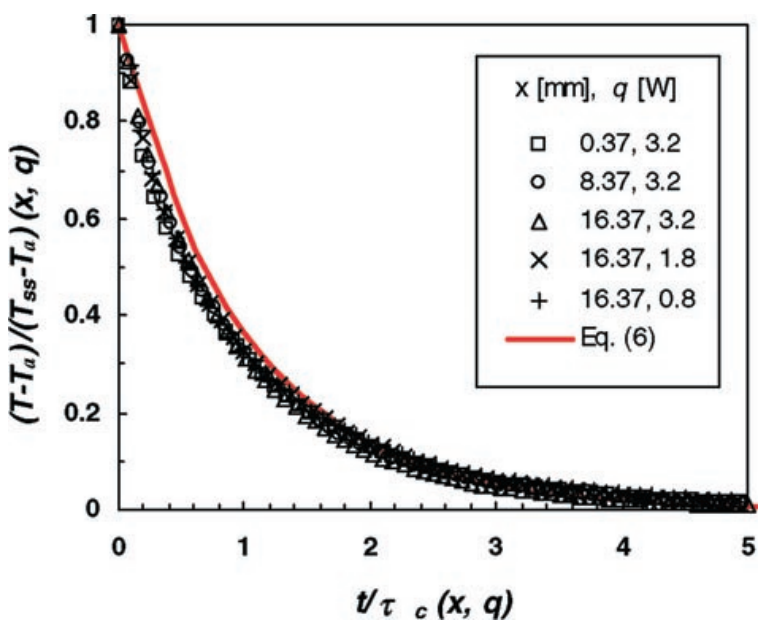

(b)

Figure 5. Normalized temperature time response to a step-current input under natural convection for: $(a)$ the heating-up process and (b) the cooling-down process.

area for the natural convection heat transfer, resulting in a faster cooling-down process. After $105 \mathrm{~s}$, the temperature of the entire device starts decrease and reaches the steady state of uniform, ambient temperature after about $595 \mathrm{~s}$. Throughout the cooling-down process, the temperature distribution along the device surface is almost uniform except at the heater location.

4.1.2. Measured characteristic time scales. The time evolution of the local transient temperature due to a stepcurrent input is summarized in figures $5(a)$ and $5(b)$ for the heating-up and cooling-down process, respectively. All the curves, for different locations and different power levels, collapse onto a single exponential function when a local time constant, either $\tau_{h}$ or $\tau_{c}$, and the local steady-state temperature, $T_{s s}$, are used as the normalizing parameters. Evidently, under natural convection, the temperature response of the device to a step-power input is either an exponential rise for the heating-up process or a fall for the cooling-down process. This is typical of the response of a first-order system.

The time constant is a natural parameter characterizing a first-order system, for which it is defined as the time 


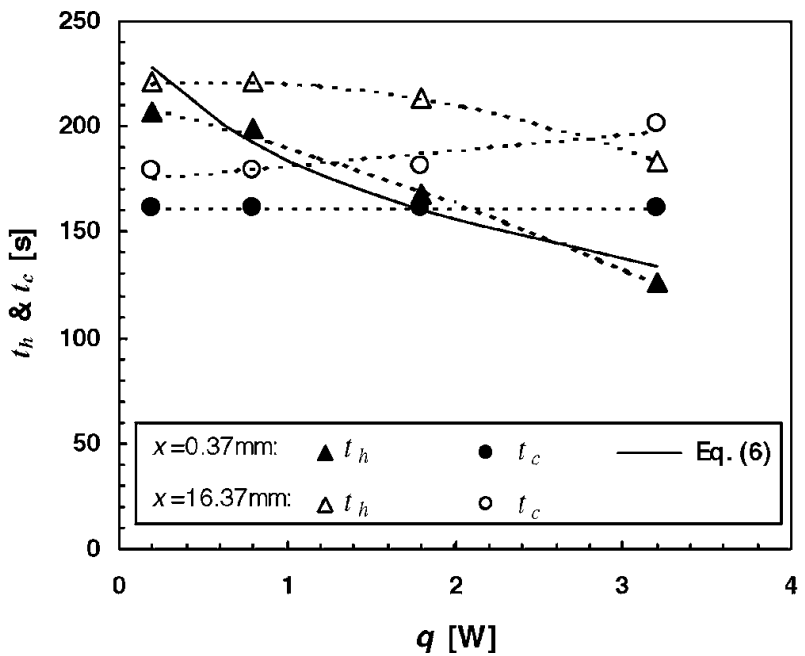

(a)

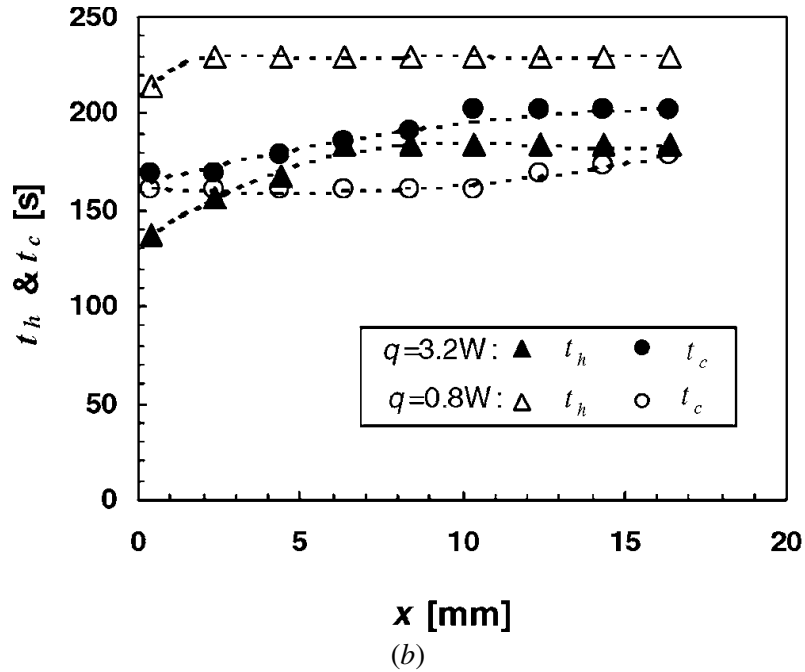

Figure 6. The rise time for the heating-up process and the fall time for the cooling-down process as functions of: $(a)$ the input power level and $(b)$ the sensor location along the device.

required for the system to reach $63.2 \%$ of its steady-state level. However, this is not a convenient parameter with which to characterize higher-order systems. A more convenient parameter is the temperature rise time for heating-up process or the fall time for cooling-down process, which is defined as the time required for a system to achieve a response of $90 \%$ of the steady-state level. For a first-order system, the rise time or fall time is 2.3 times the corresponding time constant. The temperature rise time, $t_{h}$, and fall time, $t_{c}$, are plotted as functions of either the input power level or the sensor location in figures $6(a)$ and $6(b)$, respectively, and both time scales are in the range of 150-220 s. The temperature rise time decreases with increasing input power, shown in figure $6(a)$, while the fall time increases slightly with increasing input power. Furthermore, the temperature rise time and fall time increase along the device for the higher power level of $3.2 \mathrm{~W}$, figure $6(b)$, while both are quite uniform for the lower power of $0.8 \mathrm{~W}$.

4.1.3. Estimated time scales. The transient temperature of the thermal system is governed by the energy balance between the heat conduction through the Si substrate, natural convection from the chip surfaces to the ambient and the input power by the heater. The ratio of the internal conduction resistance to external convection resistance is defined as the Biot number:

$$
B i=\frac{h L_{s}}{k_{s}}
$$

where $L_{s}$ is a characteristic length scale, $h$ is the heat transfer coefficient of the fluid and $k_{s}$ is the thermal conductivity of the Si substrate. For $B i<0.1$, the lumped system analysis model is applicable [13], in which the temperature distribution during transients within the solid at any instance is assumed to be uniform.

The measured time response suggests that the transient behavior is dominated, for a given power dissipation level, by the balance between the heat stored as thermal energy within the device and the heat transferred from the device surface to the ambient by natural convection. The coefficient of heat transfer for the natural convection, $h_{N}$, is estimated as follows [13]:

$$
h_{N}=1.32\left(\frac{T-T_{a}}{L_{s}}\right)^{1 / 4}
$$

where $T$ is the device surface temperature and $T_{a}$ is the ambient temperature. In order to account for the effect of the package, to which the device chip is attached, the size of the package, $38 \mathrm{~mm} \times 32 \mathrm{~mm} \times 1.5 \mathrm{~mm}$, is used in the estimation rather than the chip size, $25 \mathrm{~mm} \times 12 \mathrm{~mm} \times 1 \mathrm{~mm}$. The value of the heat transfer coefficient is in the range of $6-12 \mathrm{~W} \mathrm{~m}^{-2} \mathrm{~K}^{-1}$ for the current test conditions. This depends on the temperature, which is a function of the power input. Thus the higher the power input, the larger the heat transfer coefficient. The corresponding Biot number is in the order of $10^{-3}$. Hence, the lumped system analysis model is valid, and the device temperature gradients within the substrate can be neglected. Consequently, the governing equation is given by

$$
\rho_{s} c_{p_{s}} V_{s} \frac{\mathrm{d} T}{\mathrm{~d} t}+h_{N} A_{N}\left(T-T_{a}\right)=I^{2} R
$$

where $T$ is the device temperature as a function of time $t ; \rho_{s}$ and $c_{p s}$ are the density and specific heat of the Si substrate, respectively; $V_{s}$ is the volume of the chip, $A_{N}$ the surface areas for the natural convection heat transfer, and $I^{2} R$ is the input power from the heater.

Equation (3) is a first-order ordinary differential equation, and can be easily solved subject to the proper initial condition for either the heating-up or the cooling-down process:

$$
\begin{array}{rr}
T(t=0)=T_{a} & \text { (heating-up process) } \\
T(t=0)=T_{s s} \quad \text { (cooling-down process). }
\end{array}
$$

The corresponding solutions are given by

$$
\begin{array}{rlrl}
\frac{T-T_{a}}{T_{s s}-T_{a}} & =1-\mathrm{e}^{-\left(2 h_{N} / \rho_{s} c_{p_{s}} d\right) t} & \quad \text { (heating-up process) } \\
\frac{T-T_{a}}{T_{s s}-T_{a}}=\mathrm{e}^{-\left(2 h_{N} / \rho_{s} c_{p_{s}} d\right) t} & \quad \text { (cooling-down process) }
\end{array}
$$


where $d$ is the Si substrate thickness, $d=V_{s} /\left(A_{N} / 2\right)$ and $T_{s s}$ is the steady-state temperature. Thus, the time constant associated with this model for either heating-up or coolingdown process is given by

$$
\tau_{h}=\tau_{c}=\frac{\rho_{s} c_{p_{s}} d}{2 h_{N}}
$$

The estimated time scales, based on equation (6), depend on the heat transfer coefficient, which in turn is a function of the power input. Since the heat transfer coefficient increases with the temperature, the rise time and the fall time should decrease with increasing power input. The estimated decrease of the rise time with the increased power input, plotted in figure 6(a), agrees well with the measured trend for the heating-up process. However, it is not clear why the measured fall time for the cooling-down process is independent of the power input.

4.1.4. Equivalent thermal impedance circuit. The transient performance of the thermal system can be modeled by the thermal impedance concept [13]. Under the natural convection condition, the equivalent thermal circuit of the system is shown in figure 7 . The thermal time constant for the natural convection system, $\tau_{N}$, may be expressed as

$$
\tau_{N}=R_{N} C_{s}
$$

where

$$
C_{s}=\rho_{s} V_{s} c_{p_{s}}
$$

and

$$
R_{N}=R_{s}+R_{n c v}
$$

with

$$
R_{s}=\frac{1}{k_{s} A_{c s}} \quad R_{n c v}=\frac{1}{h_{N} A_{N}} .
$$

Here $R_{s}$ is the thermal resistance for heat conduction in the substrate, $R_{n c v}$ is the thermal resistance for natural convection and $C_{s}$ is the substrate thermal capacitance. $A_{c s}$ is the area of heat conduction across the substrate and $l$ is the length of the device. The thermal resistance for heat conduction in the substrate is estimated to be about $6 \%$ of that for natural convection, and can be neglected. Thus, the time constant of the equivalent thermal circuit is the product of the substrate thermal capacitance and the thermal resistance of the natural convection, which is identical to the expression in equation (6). The good agreement between the estimated transient temperature based on the equivalent thermal circuit and the measured temperature response is demonstrated in figure 5 for the heating-up and cooling-down processes.

4.1.5. Device steady-state temperature. Equation (3) also predicts that the steady-state temperature should be a linear function of the input power as follows:

$$
T_{s s}-T_{a}=\frac{I^{2} R}{2(w+d) l h_{N}} \propto q
$$

where $w$ is the width of the device. Indeed, the measured device steady-state temperature, plotted in figure $8(a)$, increases linearly with the power input with a slope of

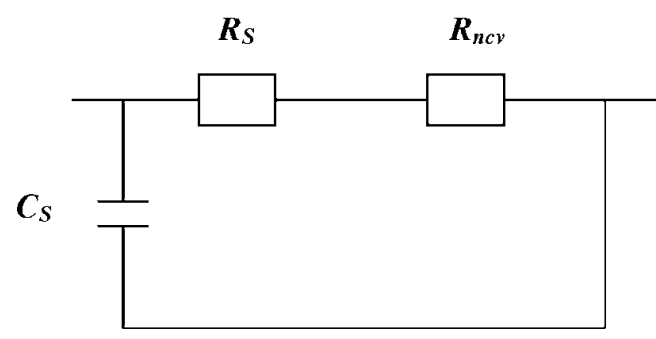

(a)

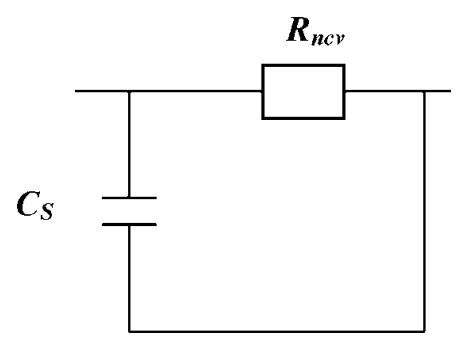

(b)

Figure 7. Equivalent thermal impedance circuit of the natural convection system for: $(a)$ the heating-up process and $(b)$ the cooling-down process.

$52.5 \mathrm{~K} \mathrm{~W}^{-1}$ for all locations. The steady-state temperature estimated by equation (11) fits very well the experimental data.

The steady-state temperature distribution along the device $x$, although neglected in the time response calculations, can still be determined. It is essentially a result of the balance between the conduction through the silicon substrate, natural convection from the device surface to the ambient air and the input power as follows:

$$
k_{s} d \frac{\partial^{2} T}{\partial x^{2}}-2 h_{N}\left(T-T_{a}\right)=I^{2} R .
$$

The temperature is then expected to decrease exponentially as a function of the distance from the heater with a characteristic length scale, $l_{c}$, given by

$$
l_{c}=\left(\frac{2 h_{N}}{k_{s} d}\right)^{-1 / 2} .
$$

For the present device, the length scale is about $50 \mathrm{~mm}$. However, the actual distance between the heater and the last sensor is only $18 \mathrm{~mm}$, which is about one-third of the estimated length scale. Consequently, the measured steady-state temperature distributions, shown in figure $8(b)$ for several input power levels, appear nearly linear since the device is quite short.

\subsection{Transient temperature under forced convection}

4.2.1. Measured temperature response. The time response of the device to a step-current input under forced convection was also investigated for the same input power range. DI water was driven into the microchannel through the flow inlet located near the heater, shown in figure 1 , while the outlet was about $18.6 \mathrm{~mm}$ away from the heater. The driving pressure was kept constant at $100 \mathrm{kPa}$, providing a water volume flow rate of about 
Transient temperature performance of an integrated micro-thermal system

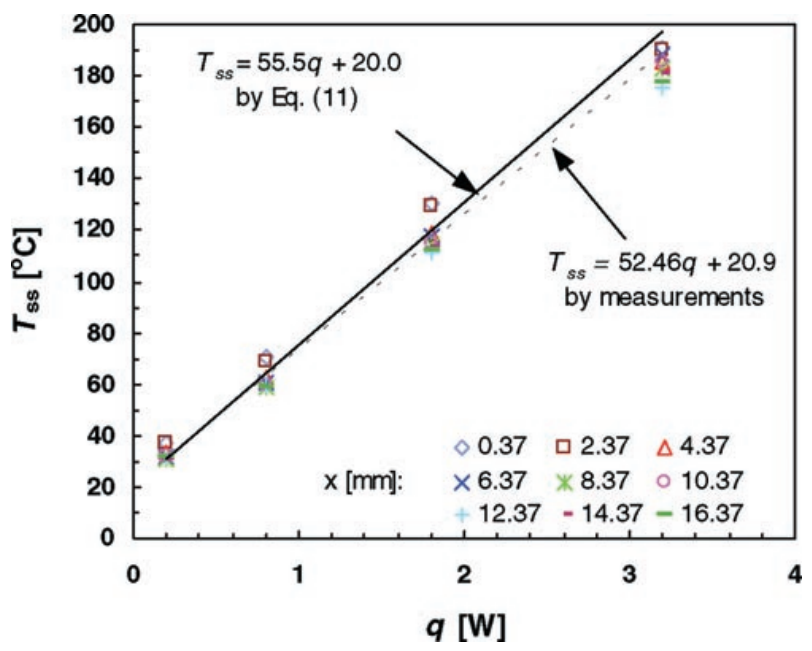

(a)

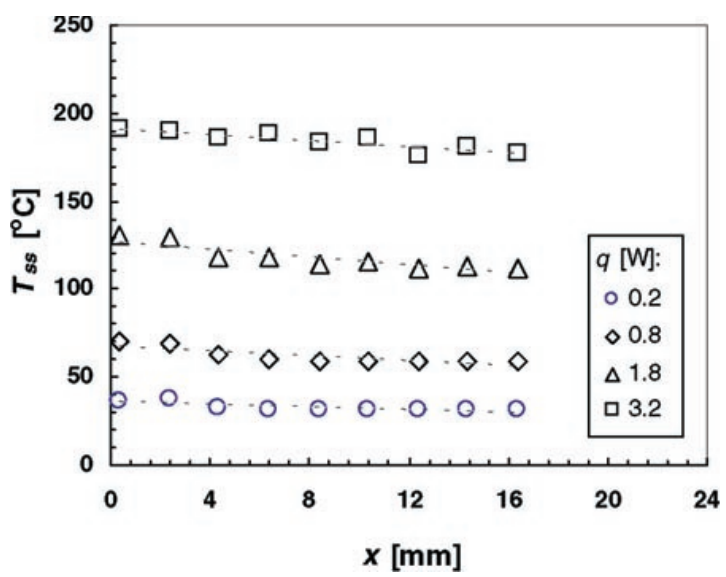

(b)

Figure 8. Device steady-state temperature to a step-current input under natural convection as a function of: $(a)$ the input power level and $(b)$ the distance from the heater.

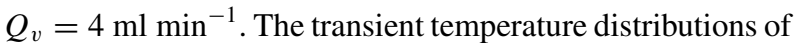
the device under forced convection for both of the heatingup and cooling-down processes are shown in figures $9(a)$ and $9(b)$, respectively. In the heating-up process, the temperature increases to a maximum level in a very short time of about $14 \mathrm{~s}$. The temperature then drops gradually to the steady state in about $84 \mathrm{~s}$. During the cooling-down process, the temperature drops to the steady-state temperature within $35 \mathrm{~s}$. Unlike the case of natural convection, the temperature increases along the device, from the inlet to the outlet, mainly due to the forced convection cooling effect. The temperature of the DI water at the inlet is $20^{\circ} \mathrm{C}$. Thus heat is transferred between the channel walls and the forced-convection fluid due to the temperature difference, and the temperature of the cooling water increases with downstream distance as it approaches the wall temperature.

The typical time response of device transient temperature to a step-current input under forced convection is shown in figures $10(a)$ and $10(b)$. In the heating-up process the transient temperature demonstrates a clear overshoot before it reaches the steady-state temperature. The result is different from previously published numerical simulations where the temperature monotonically approaches the steady-state

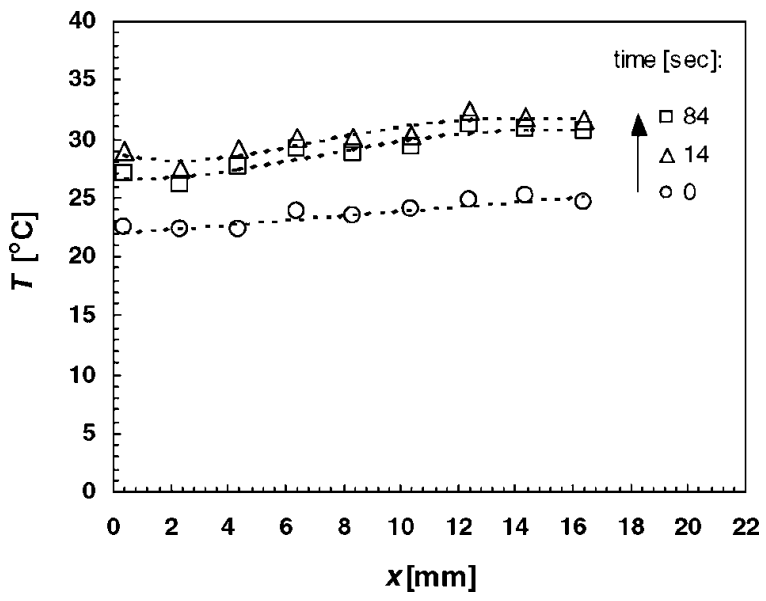

(a)

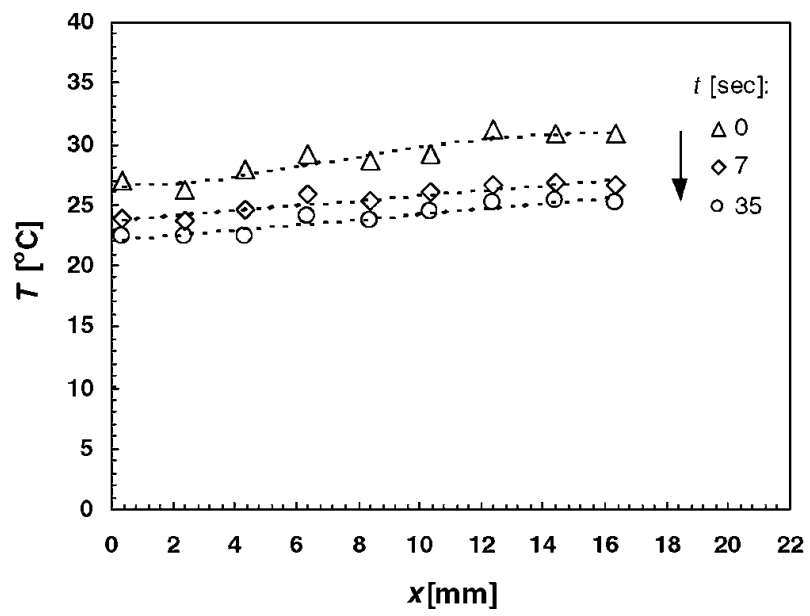

(b)

Figure 9. Transient temperature distribution along the device to a step-current input under forced convection for: $(a)$ the heating-up process and $(b)$ the cooling-down process. $\left(Q_{v}=4 \mathrm{ml} \mathrm{min}^{-1}\right.$, $q=1.8 \mathrm{~W}$.)

temperature [7]. The temperature increases rapidly from its initial to its maximum value, and then monotonically decreases to its eventual steady-state value. At the initial sharp temperature increase, the heat transfer mode is dominated by heat conduction through the device substrate, which is a faster mechanism. When the wall temperature is high enough, a large temperature difference exists across the wall-fluid interface. As a result the forced convection becomes the dominant heat transfer mechanism. Then, the fluid temperature increases and the wall temperature decreases until the system reaches its steady state. In the cooling-down process, the temperature drops quickly to the ambient temperature due to the enhanced cooling effect by the forced convection.

4.2.2. Measured characteristic time scales. The temperature time rise and fall time for this system are still defined as the time required to attain $90 \%$ of the steadystate value. In the case where the system exhibits overshoot behavior, for example in the heating-up process, the response time is usually stated as the time for the system to settle to within $\pm 10 \%$ of the steady-state value. Of course, the 


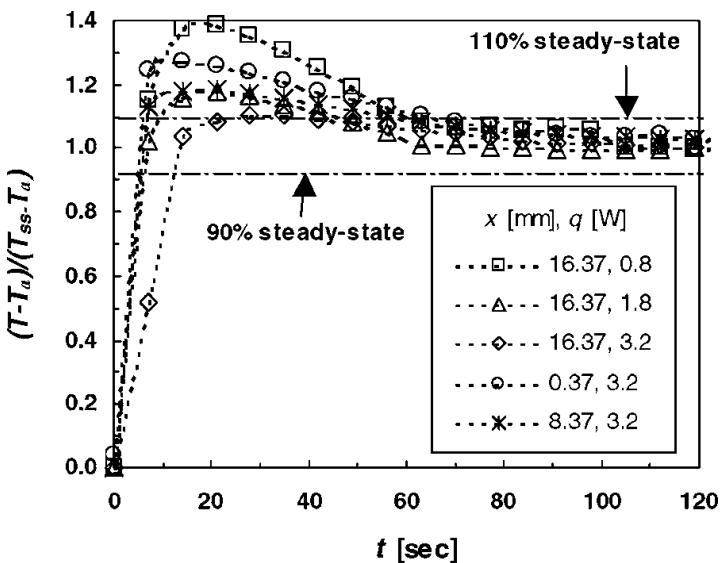

(a)

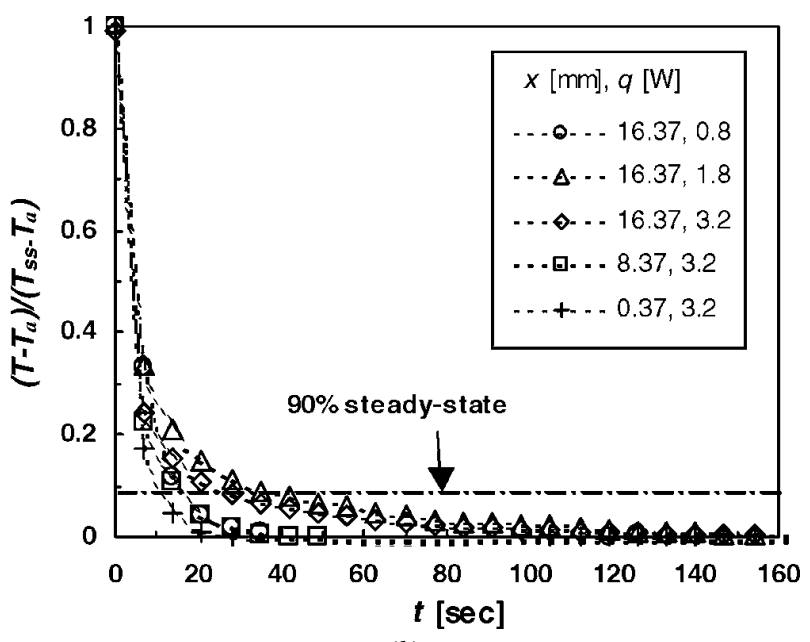

(b)

Figure 10. Normalized temperature time response to a step-current input under forced convection for: $(a)$ the heating-up process and $(b)$ the cooling-down process. $\left(Q_{v}=4 \mathrm{ml} \mathrm{min}^{-1}\right.$.)

rise and fall times will be equal to the response time, if the system response is monotonic such as in the cooling-down process. However, in the heating-up process the rise time, $t_{r}$, dominated by the conduction mechanism, is much smaller than the response time, $t_{\text {hres }}$, dominated by the convection mechanism. The dependence of the device rise and fall times and response time on the input power as well as on the distance from the heater under forced convection is shown in figures $11(a)$ and $11(b)$, respectively. The temperature rise time increases with the input power and is less than $10 \mathrm{~s}$ for the power input range tested, figure 11(a), while the response time for the heating-up process is in the range of 20-60 s. On the other hand, the fall time for the coolingdown process, equal to the response time, is less than $10 \mathrm{~s}$. Both the rise and fall times are almost uniform along the entire chip, as shown in figure 11(b). A slight decrease of the heating-up response time and a slight increase of the fall time are observed with increasing distance from the heater under forced-convection conditions. In comparison with the case of natural convection, the response time drops from 170 to $50 \mathrm{~s}$ for the heating-up process, and from 190 to $20 \mathrm{~s}$ for the cooling-down process. Moreover, the temperature rise time under forced convection is less than $10 \mathrm{~s}$ throughout the

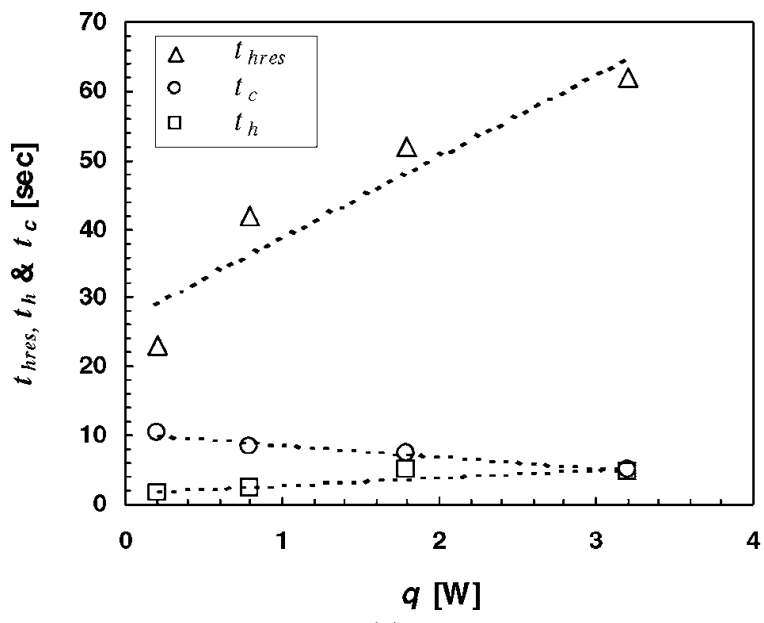

(a)

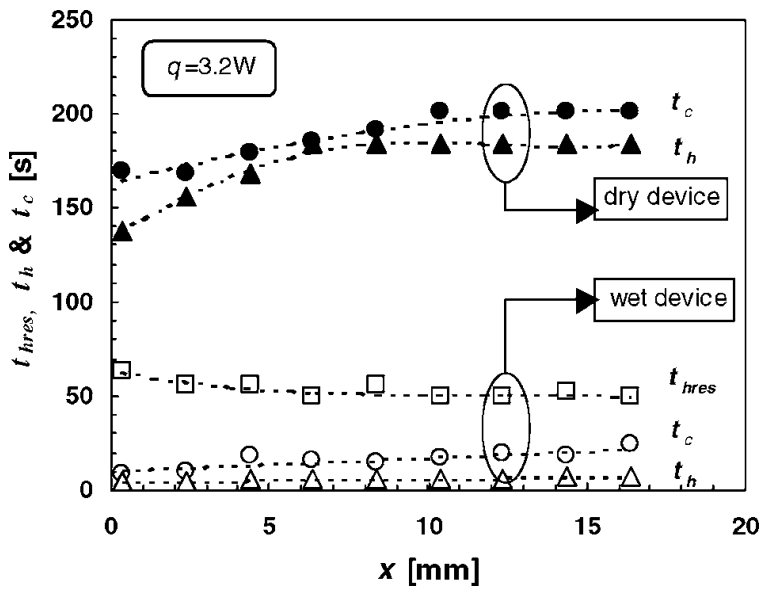

(b)

Figure 11. The rise time for the heating-up process and the fall time for cooling-down process as functions of: $(a)$ the input power level and $(b)$ the sensor location along the device. $\left(Q_{v}=4 \mathrm{ml} \mathrm{min}^{-1}\right.$.)

whole chip. Thus, the forced convection reduces this thermal time scale of the microsystem by one order of magnitude.

4.2.3. Mathematical modeling. The transient temperature of the thermal system is governed by the energy balance between the heat conduction through the Si substrate, natural convection from the chip surfaces to the ambient, forced convection by channel fluid flow and the heater input power. The device spanwise temperature distribution was found to be uniform in a previous study [11]. Thus, the one-dimensional, time-dependent, governing energy equation takes the form

$$
\begin{gathered}
\rho_{s} c_{p_{s}} V_{s} \frac{\partial T}{\partial t}+h_{N} A_{N}\left(T-T_{a}\right)+h_{F} A_{F}\left(T-T_{b}\right) \\
+\rho_{f} c_{p_{f}} Q_{v} t \frac{\partial T_{b}}{\partial t}=I^{2} R+k_{s} V_{s} \frac{\partial^{2} T}{\partial x^{2}}
\end{gathered}
$$

where $T_{b}$ is the fluid bulk temperature; $\rho_{f}$ and $c_{p f}$ are the density and specific heat of the working fluid, respectively; $Q_{v}$ is the fluid volume flow rate through the microchannels; $A_{F}$ and $h_{F}$ are the surface area and the heat-transfer coefficient for the forced-convection heat transfer across the microchannels walls, respectively. The heat transfer coefficient is estimated to be about $1000 \mathrm{~W} \mathrm{~m}^{-2} \mathrm{k}^{-1}$ for 
Transient temperature performance of an integrated micro-thermal system

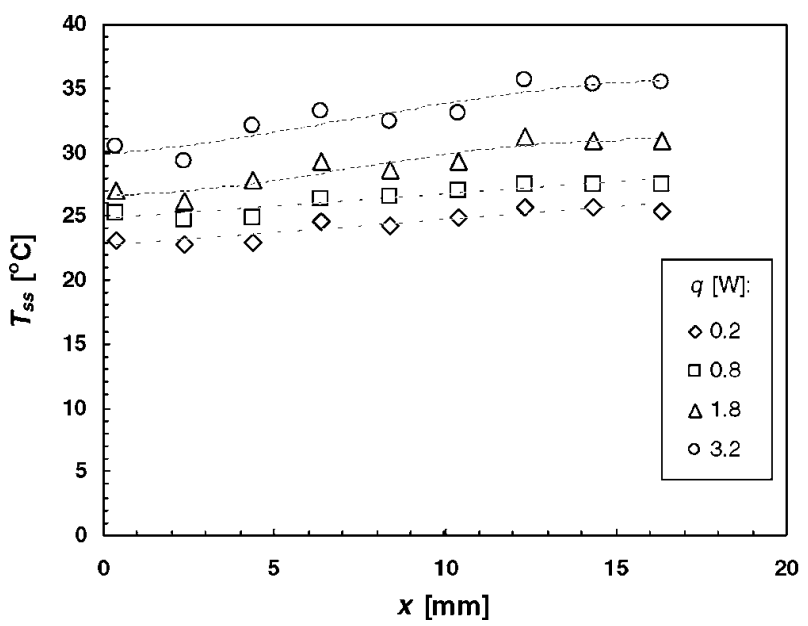

(a)

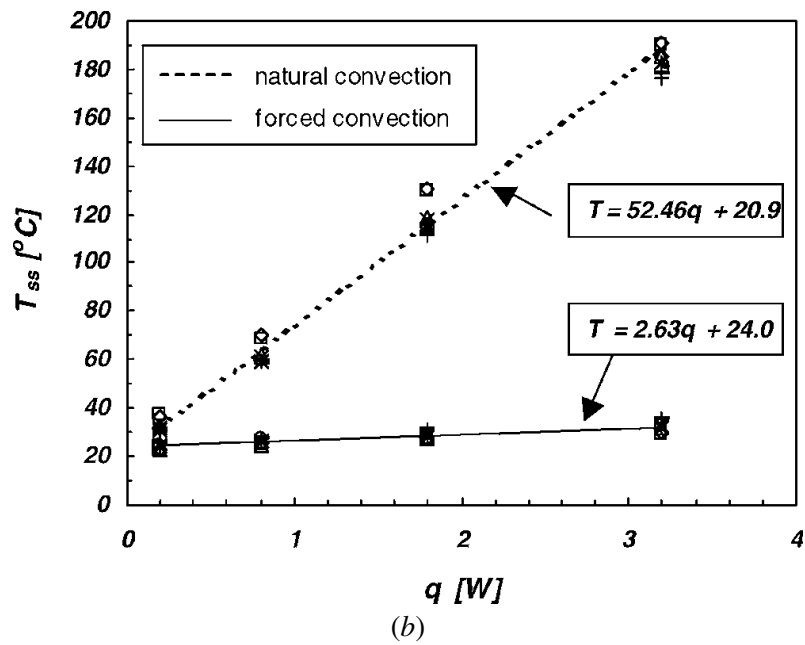

Figure 12. The device steady-state temperature for a step-current input under forced convection as a function of: $(a)$ the input power level and $(b)$ the distance from the heater. $\left(Q_{v}=4 \mathrm{ml} \mathrm{min}^{-1}\right.$.)

single-liquid forced convection [14]. The corresponding Biot number is about 0.17 , larger than the critical value of 0.1 . Hence, the lumped system analysis model is not valid, and the conduction term cannot be neglected. Furthermore, both the substrate temperature and the fluid bulk temperature are time dependent and unknown. The resulting governing equation is fairly complicated, especially taking into account the complexity of the boundary condition, which is neither uniform heat flux nor constant temperature. The transient behavior, therefore, cannot be described by a simple, firstorder partial differential equation. The higher-order behavior is demonstrated by the measured time response depicted in figure 10, which is clearly different from the natural convection behavior shown in figure 5 .

4.2.4. Steady-state temperature. The dependence of the steady-state temperature, $T_{s s}$, on either the distance from the heater, $x$, or the input power, $q$, is shown in figures $12(a)$ and $12(b)$, respectively. In general, the temperature increases as the distance from the heater increases, and the positive slope increases with the input power, shown in figure $12(a)$. The fluid absorbs heat from the local heater

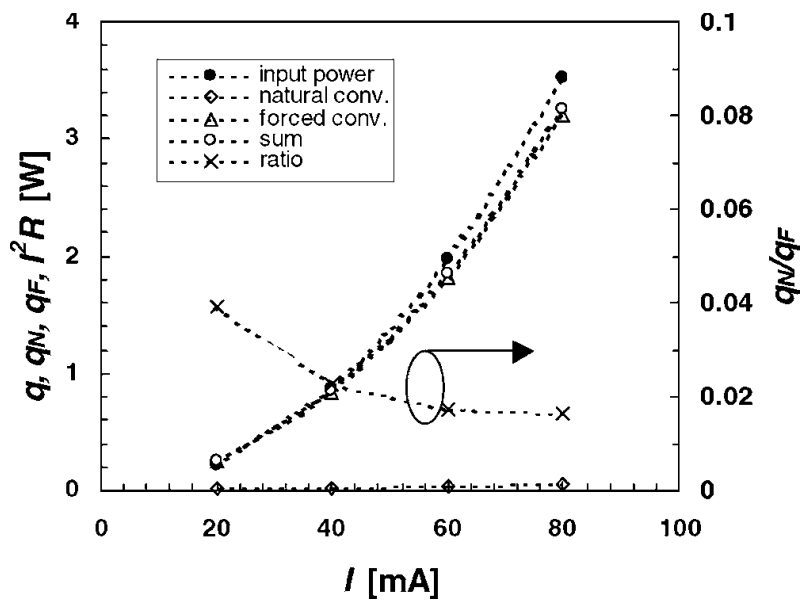

Figure 13. Relative contribution of the natural convection and the forced convection heat transfer.

at the inlet and transfers heat to the substrate downstream. Under forced convection with any flow rate, device steadystate temperature level of the device for the entire tested input power range is less than $35^{\circ} \mathrm{C}$, and the maximum temperature difference over the device is less than $5^{\circ} \mathrm{C}$. The comparison of device steady-state temperature as a function of the input power under natural convection and forced convection is shown in figure $12(b)$. The temperature under the forcedconvection case also increases linearly with the input power, similar to the natural convection case. However, the slope for the device under forced convection, about $2.6 \mathrm{~K} \mathrm{~W}^{-1}$, is more than one order of magnitude lower than the slope for the device under natural convection, about $52.5 \mathrm{~K} \mathrm{~W}^{-1}$, due to the enhanced forced-convection heat transfer.

Assuming the temperature along the device at steady state is uniform, the energy balance of the thermal system can be re-written as

$$
q=q_{N}+q_{F}
$$

where $q_{N}$ and $q_{F}$ are the corresponding heat-transfer rate by natural convection and forced convection. Thus,

$$
\begin{gathered}
q_{F}=h_{F} A_{F}\left(T_{\text {out }}-T_{\text {in }}\right) \\
q_{N}=h_{N} A_{N}\left(T-T_{a}\right)
\end{gathered}
$$

where $T_{\text {in }}$ and $T_{\text {out }}$ are the channel inlet and outlet temperatures. A comparison between the contribution of natural and forced convection is demonstrated in figure 13 . It is clear that most of the heat generated by the heater is removed by forced convection, while the heat removed by natural convection accounts for only $2-5 \%$ of the total heat dissipation.

\section{Device frequency response to a sinusoidal voltage input}

The transient response of the device temperature to periodic power input was also investigated. A sinusoidal voltage, $V$, signal given by

$$
V(t)=\frac{V_{\max }+V_{\min }}{2}+\frac{V_{\max }-V_{\text {min }}}{2} \sin (2 \pi f)
$$




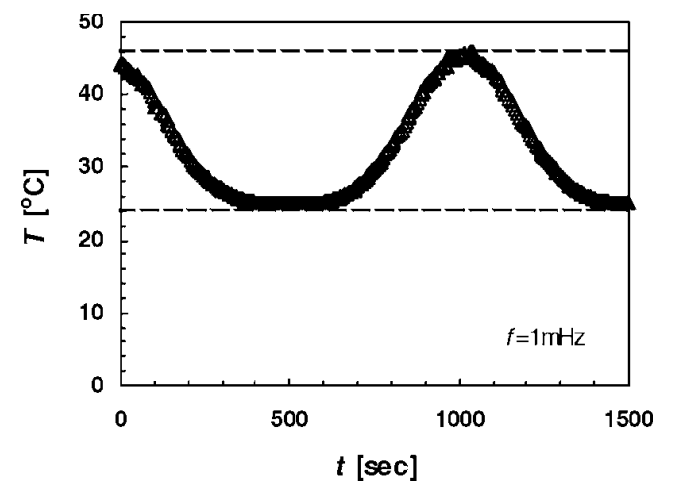

(a)

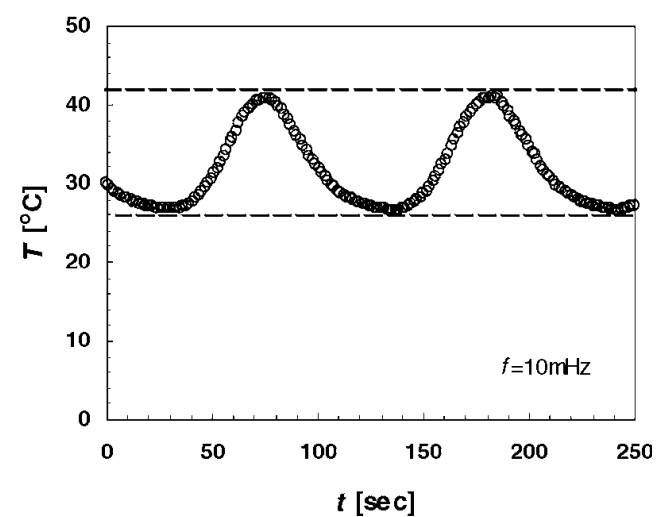

(b)

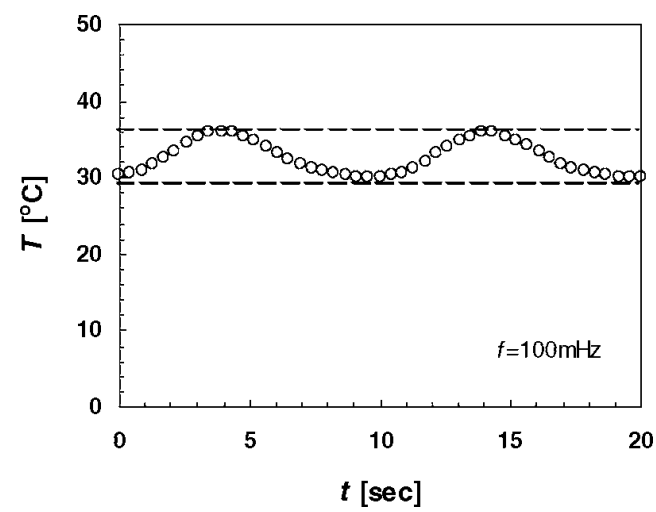

(c)

Figure 14. Measured device temperature under forced convection for a sinusoidal power input with a frequency of: $(a) 1,(b) 10$ and

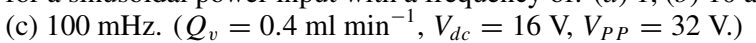

was applied to the heater. Here, $f$ is the frequency; $V_{\max }$ and $V_{\text {min }}$ are the signal maximum and minimum values, respectively. The periodic temperature response can be modeled as

$$
T(t)=\frac{T_{\max }+T_{\min }}{2}+\frac{T_{\max }-T_{\min }}{2} \sin (2 \pi f+\varphi)
$$

where $\varphi$ is the phase shift. The temperature maximum, $T_{\text {max }}$, and minimum, $T_{\min }$, depend on the parameters of the input voltage signal as well as on the flow rate of the convection fluid.

A typical transient temperature response of the device to a sinusoidal voltage input of varying frequency is shown in figure 14. It is clear that the curves are not perfect sinusoidal

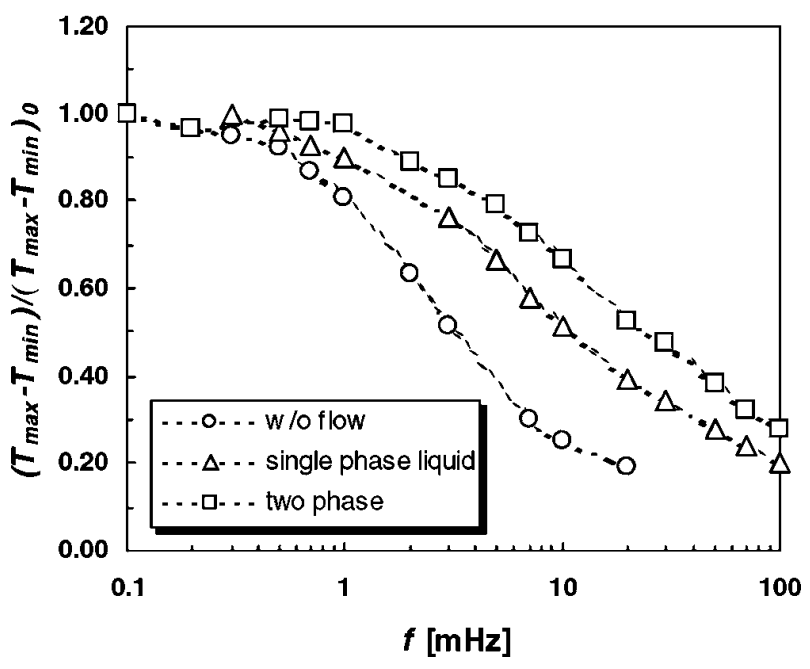

Figure 15. Comparison of the measured frequency response for different flow conditions.

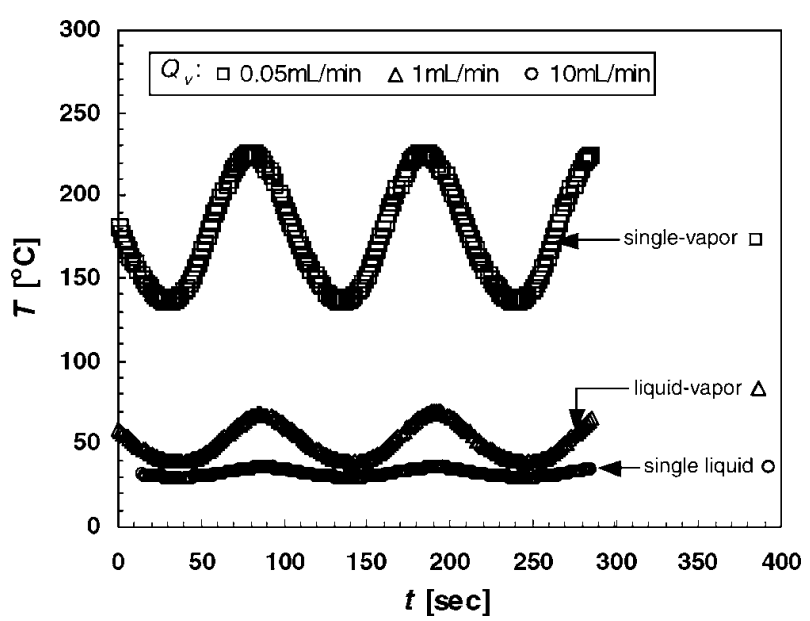

(a)

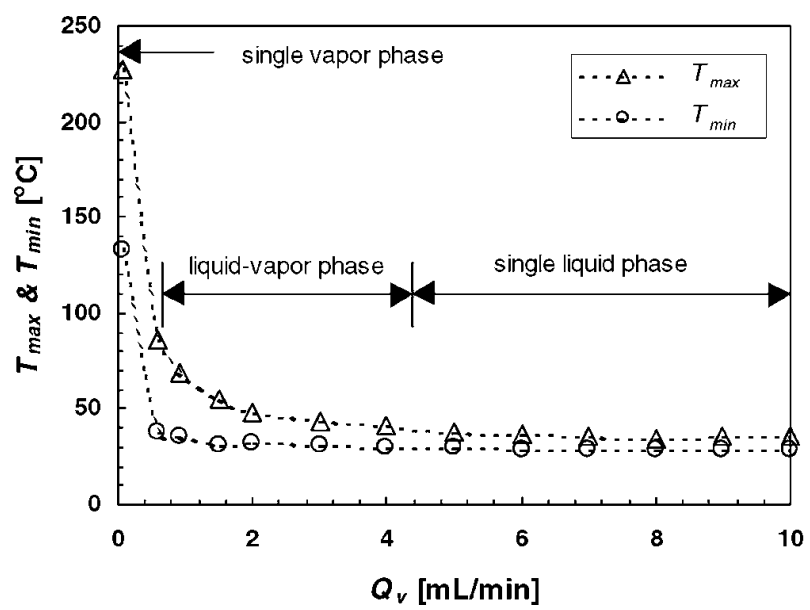

(b)

Figure 16. The effect of flow-rate on $(a)$ the periodic device temperature and $(b)$ the maximum and minimum temperatures due to a sinusoidal power input. $\left(V_{d c}=40 \mathrm{~V}, V_{p p}=32 \mathrm{~V}\right.$.)

functions, since the heating-up rise time is much shorter than the cooling-down fall time. Furthermore, the amplitude of the temperature fluctuations decreases with increasing 


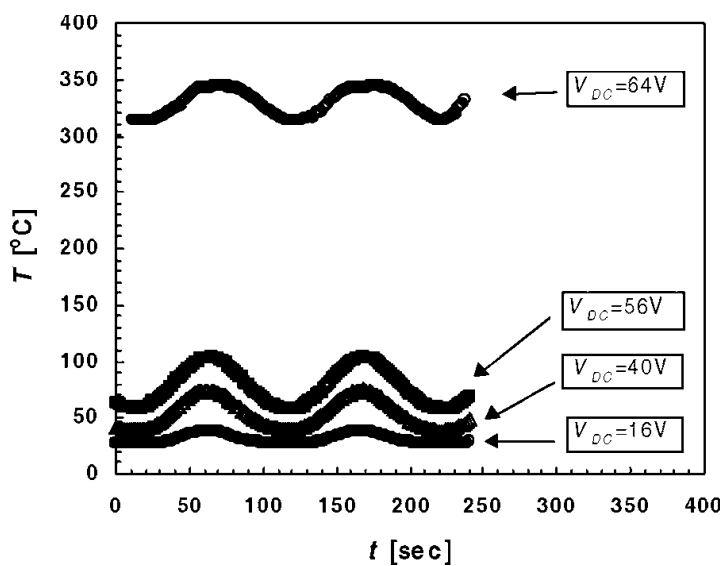

(a)

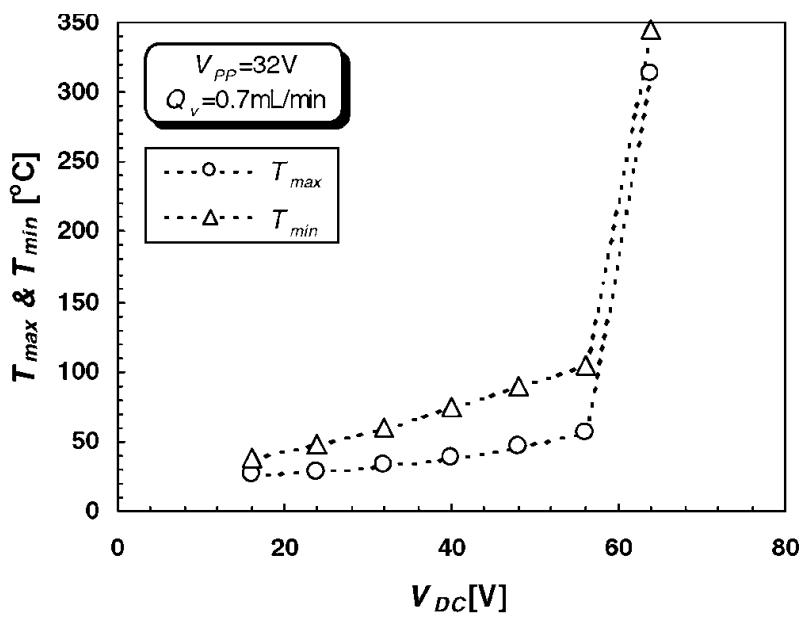

(b)

Figure 17. The effect of the dc input voltage on: $(a)$ the periodic device temperature and $(b)$ the maximum and minimum temperatures. $\left(V_{p p}=32 \mathrm{~V}, Q_{v}=0.7 \mathrm{ml} \mathrm{min}^{-1}\right.$.)

frequency, from about $20^{\circ} \mathrm{C}$ at $f=1 \mathrm{mHz}$, to about $16^{\circ} \mathrm{C}$ at $f=10 \mathrm{mHz}$ and to about $7^{\circ} \mathrm{C}$ at $f=100 \mathrm{mHz}$. This is similar to previously published numerical simulations [7], although the shape of the computed response is closer to triangular than the sinusoidal function, unlike the wave form obtained in the experiment. The frequency response of the device temperature for three cases: natural convection, single-liquid-phase forced convection and liquid-vaporphase forced convection is summarized in figure 15 . The normalized peak-to-peak value of the periodic temperature response $\left(T_{\max }-T_{\min }\right) /\left(T_{\max }-T_{\min }\right)_{0}$ decreases as a function of the input frequency; $\left(T_{\max }-T_{\min }\right)_{0}$ being the peak-to-peak value of the temperature oscillations for the lowest tested frequency $f_{0}=0.1 \mathrm{mHz}$. The curves demonstrate that the frequency response of the device under natural convection can be improved by forcing liquid through the microchannels, which enhances the heat transfer rate. Further improvement can be achieved by allowing a phase change inside the channels due to the fast evaporation process.

\subsection{Effects of operational conditions}

The effect of flow rate on the transient temperature is shown in figure $16(a)$ for an input voltage signal with $f=10 \mathrm{mHz}$.

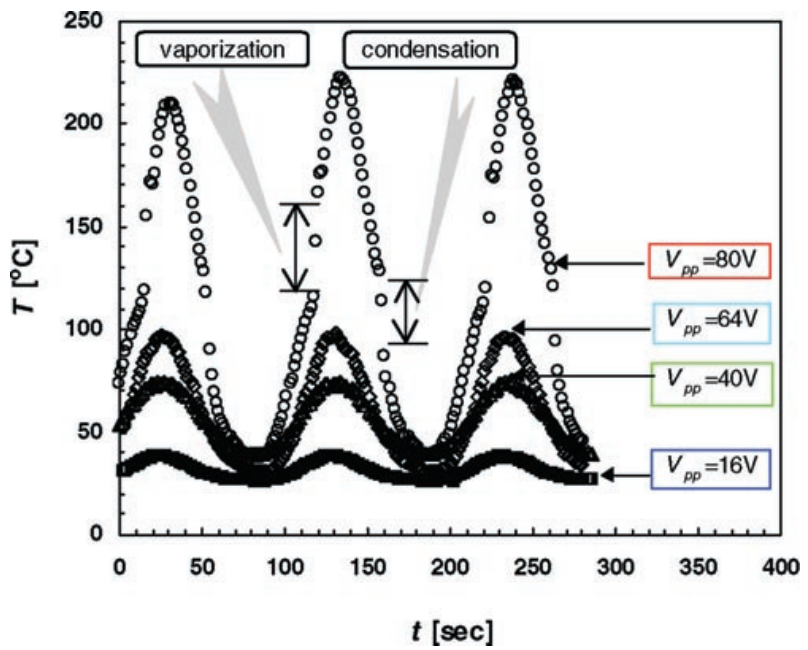

(a)

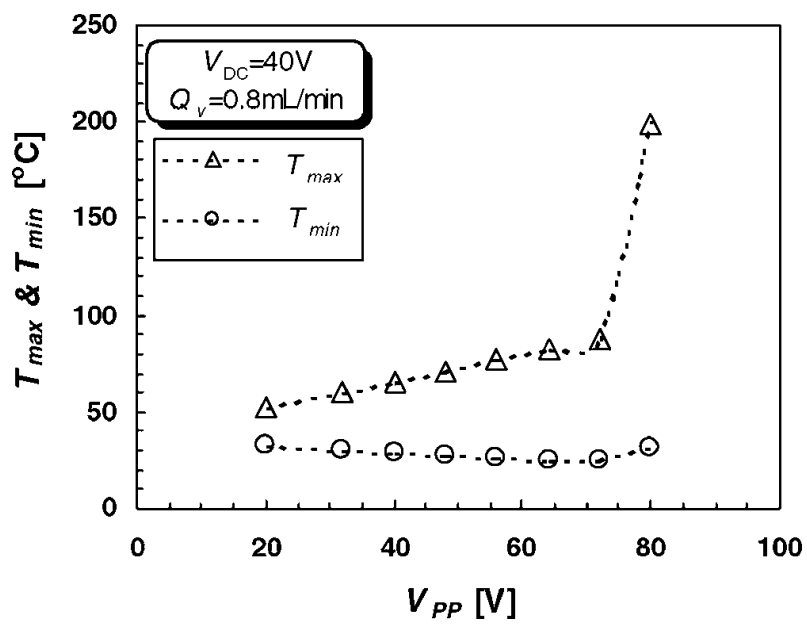

(b)

Figure 18. The effect of the amplitude of the input voltage on: (a) the periodic device temperature and $(b)$ the maximum and minimum temperatures. $\left(V_{d c}=40 \mathrm{~V}, Q_{v}=0.8 \mathrm{ml} \mathrm{min}^{-1}\right.$.)

It is clear that regardless of the conditions of the fluid phase, i.e. whether the flow is in single-liquid, liquid-vapor or single-vapor phase, all the curves are sinusoidal with a frequency of $10 \mathrm{mHz}$. The dependence of the maximum and minimum temperature on the flow rate is shown in figure $16(b)$. As long as the flow rate is high enough to keep the fluid either in a single-liquid or liquid-vapor phase, the maximum temperature gradually decreases with an increasing flow rate, while the minimum temperature is almost constant. However, both the minimum and the maximum temperatures increase dramatically at low flow rate, when the exit fluid is in a single-vapor phase. The incremental decrease in the flow rate leads to a single-vapor phase throughout the channels during the entire thermal cycle. This unstable condition results in the complete dryout of the device with exceedingly high temperature which, in many instances, resulted in a damaged device.

The input power level can be controlled by varying either the average, $V_{d c}=\left(V_{\min }+V_{\max }\right) / 2$, or the peak-to-peak value, $V_{P P}=V_{\text {max }}-V_{\text {min }}$, of the voltage signal applied to the heater. The effect of the dc level of the sinusoidal input power, $V_{d c}$, on the transient temperature response is 
presented in figure 17(a). The device temperature increases with an increasing dc power level, while the amplitude of the temperature oscillations does not change much for all fluid phase conditions. The dependence of the maximum or minimum temperature on $V_{d c}$, shown in figure $17(b)$, is very similar. As soon as the flow is in a single-vapor phase, around $V_{d c}=64 \mathrm{~V}$, both the minimum and the maximum temperature exceed $300^{\circ} \mathrm{C}$, dryout occurs and the device can no longer function.

The effect of the peak-to-peak level of the sinusoidal input power, $V_{P P}$, on the transient temperature response is depicted in figure $18(a)$. At the highest input amplitude, $V_{P P}=80 \mathrm{~V}$, the temperature response is no longer sinusoidal. A sudden increase during the heating-up and a sudden decrease during the cooling-down portions of the cycle can be observed at a device temperature of about $120^{\circ} \mathrm{C}$. This result suggests that both complete vaporization and condensation processes take place in a single thermal cycle, which prevent the occurrence of a dryout. Thus, temperature cycling may allow the device to reach high temperatures while protecting it from the damage associated with dryout. Interestingly, the minimum temperature does not change as the power amplitude increases, as shown in figure $18(b)$. In contrast, the maximum temperature increases almost linearly with the input amplitude. However, the maximum temperature increases dramatically when the vaporization-condensation conditions develop. A large peak-to-peak temperature range, up to $180^{\circ} \mathrm{C}$, can be achieved in the amplitude-controlled mode. This operation mode provides a potential approach to carry out thermal cycling when a large temperature difference within a single cycle is required, such as in chemical or biological applications.

\section{Conclusions}

A novel microchannel heat sink has been constructed with a localized microheater and distributed temperature microsensors to allow for the experimental investigation of the transient performance of the integrated thermal microsystem.

The device time response to a step-current input for either the heating-up or the cooling-down processes, under natural convection, is the exponential rise or decay under all the conditions tested. Natural convection is the dominant heat transfer mechanism and the system exhibits first-order behavior. The device heating-up rise time decreases with increasing input power, while the cooling-down fall time varies very little. Both the rise time or the fall time are in the range of 130-220 s. Under forced convection, the device temperature overshoots the steady-state value in the heating-up process, exhibiting a higher-order response. The cooling-down time response, although monotonic, is not exponential. The device rise time and fall time are reduced by one order of magnitude, to about 10-20 s, due to the forced convection heat transfer. Moreover, forced convection leads to a significantly lower operational temperature, less than $35^{\circ} \mathrm{C}$, for the input power range tested. Simplified thermal impedance models show similar trends as the experimental results. However more factors, especially the effect of the package, should be considered in order to obtain more accurate values.

Under a periodic input signal, dryout can suddenly occur; which usually results in a damaged device. However, operating the system under an amplitude-controlled mode, completely stable vaporization and condensation processes take place within a single thermal cycle. Thus, in this particular cycling mode, a large peak-to-peak temperature range can be achieved without the occurrence of dryout.

\section{Acknowledgment}

This work is supported by the Hong Kong Research Grant Council through RGC grant HKUST6051/99E.

\section{References}

[1] Northrupt M A, Gonzalez C, Hadley D, Hills R F, Landre P, Lehew S, Saiki R, Sninsky J J, Watson R and Watson R Jr 1995 10th Int. Conf. on Solid-State Sensors and Actuators, Transducer '95 (Sweden) pp 764-65

[2] Petersen K 1996 Proc. IEDM 96 pp 239-42

[3] Shoffner M A, Cheng J, Shoffner M A, Hvichia G E, Kricha L J and Wilding P 1996 Nucleic Acids Res. 24 375-9

[4] Cheng J, Shoffner M A, Hvichia G E, Kricha L J and Wilding P 1996 Nucleic Acids Res. 24 380-5

[5] Chaudhari A M, Woudenberg T M, Albin M and Goodson K E 1998 J. Microelectromech. Syst. 7 345-55

[6] Woolley A T, Hadley D, Landre P, deMello A J, Mathies R A and Northrupt M A 1996 Anal. Chem. 68 4081-6

[7] Zumbrunnen D A 1992 ASME J. Heat Transfer 114 85-93

[8] Rujano J R and Rahman M M 1997 ASME J. Electronic Packaging 119 239-46

[9] Jiang L, Wong M and Zohar Y 1999 Meas. Sci. Technol. 10 653-64

[10] Jiang L, Wong Y L, Wong M and Zohar Y 1999 J. Micromech. Microeng. $9422-8$

[11] Jiang L, Wong M and Zohar Y 1999 J. Microelectromech. Syst. $8358-65$

[12] Jiang L, Wong M and Zohar Y 2000 Sensors Actuators A 82 108-13

[13] Incropera F P and Dewitt D P 1990 Fundamentals of Heat and Mass Transfer (New York: Wiley)

[14] Peng X F and Peterson G P 1995 Int. J. Heat Mass Transfer $38755-8$ 